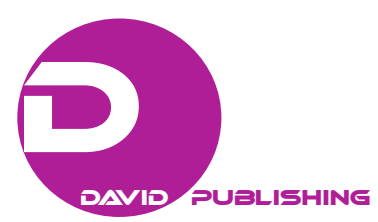

\title{
Impact of a Principal's Leadership Style on School Organizational Climate in an Arab School in Israel
}

\author{
Osama Arar, Ran Bar-Am \\ West University of Timisoara, Timisoara, Romania
}

\begin{abstract}
The study aimed at examining by quantitative research design to what extent management style affects organizational climate of schools A, B, and C of Arab sector in Israel, while comparing a test group of school A to a control group of schools B+C. The research question was: What is the impact of a principal's management style on creation of a positive school organizational climate? Quantitative data collection was conducted by means of validated questionnaires from relevant scientific literature. The findings indicate that a principal has a central role in a teacher's perception of professional autonomy. The sense of professional autonomy of a teacher is reinforced the more a teacher senses that the principal is an educational figure or a leader whom he can consult with regarding personal and professional problems. Differences were found among teachers in perception of school characteristics as providing various levels of autonomy.
\end{abstract}

Keywords: management styles, authoritative-centralized, democratic-decentralizing, organizational climate

\section{Introduction}

There is general consent on the fact that management approach (Golman, 2000), is an important component affecting performance and behavior of an organization. There is agreement amongst researchers that principals are a vital factor for the success of school (Sergiovanni, 2002).

Inclusion in management, pedagogic and technical fields which contributes to a feeling of freedom and initiative at work, will guarantee high quality of decisions and problems resolution and success of the team (Friedman, 2004; Somech, 2005).

Oplatka (2010) attributes great importance to a principal's management style over a teacher's performances, thus the system and the reciprocal relations between a teacher and a principal bring about better performance.

Several management styles exist in professional literature, such as dedicating, attentive, integrating, separated (Hen, 2004) bureaucratic, collegial, political, subjective, cultural, feedback-based management and inclusive managing (Fisher, 2003; Zafrir, 2003; Somech, 2005).

Additionally, there is significance in separation between defining management and leadership and leadership styles such as educational, mission-oriented, existential, conversion, routine, serving, charismatic, and transformational leadership (Friedman, 1993; Dagan, 2000; Bigger, 2003).

Osama Arar, Ph.D. in management, West University of Timisoara, Romania.

Ran Bar-Am, Ph.D. in management, West University of Timisoara, Romania.

Correspondence concerning this article should be addressed to Osama Arar, Jerusalem blvd 123 Tel-Aviv, Israel. 
In current study, the researcher will address to two management styles: democratic-decentralizing management and authoritative-centralized style (Friedman, 1995; Levy, 2008).

The democratic-decentralized leader, is one who has social and humane orientation towards his employees (Levy, 2008) a principal should lead by the power of his authority as a specialist with abilities of inter-personal ties rather than by the power of his formal authority, meaning, to manage a school from the center of network of inter-personal relations rather than from the top of the pyramid.

Oppositely, authoritative-centralized leader, is one with an emphasized orientation for realizing of purposes and carrying out of duties of the group. He performs his job by power of personal authority, claims loyalty for himself, he is the only person to dictate, emphasizes ambitiousness, and demands close supervision. According to this approach, a person looks for dependence on others and does not seek independence (Friedman, 1995).

The researcher will examine school climate in current study according to part of the characteristics numbered by Zak and Horovitz (1985).

\section{Research Purpose, Question, and Hypotheses}

\section{Research Purpose}

The research purpose is to examine in a quantitative research design to what extent management style affects organizational climate of schools $\mathrm{A}, \mathrm{B}$, and $\mathrm{C}$, while comparing the test group of school A to the control group of schools B+C.

\section{Research Question}

What is the effect of a principal's management style on creation of a positive school organizational climate?

\section{Research Hypotheses}

Hypothesis A: It will be found that the more democratic-decentralized is management style, thus the more positive will be school organizational climate.

Hypothesis B: It will be found that the more democratic-decentralized is management style, thus the more supportive will be educational leadership.

Hypothesis C: It will be found that the more democratic-decentralized is management style, thus adoption of innovations will be received with better understanding.

Hypothesis D: It will be found that the more democratic-decentralized is management style, thus more positive will be sense of autonomy of teachers.

\section{Research Field}

School A - that serves as a test group: The school is municipal school that includes Junior High and High school. There are about 600 pupils in the school, they are all Arab. About 80 male and female teachers teach in the school, most of them Arab, about 10 are Jewish.

School B - that serves as part of the control group: 747 pupils study in it. The teaching staff numbers about 45 teachers with a relatively high average age. The school is located in an old building. The school principal was appointed to the position just one year ago.

School C-that serves as part of the control group: About 300 pupils study in it. The teaching staff numbers about 25 male and female teachers. The school principal is a young principal who in the past served as 
a teacher in the school and due to his good skills was appointed to the position of principal.

The questionnaires were distributed to all teachers who work in the three schools, however the questionnaires were filled according to the following: From school A-18 teachers; from school B-19 teachers; from school C -19 teachers. Total of 56 participants. The demographic distribution of the sample: 48 female teachers and eight male teachers participated in the study.

\section{Research Tools}

Two validated questionnaires were used in the study.

\section{Management Style Questionnaire}

"Likert" type questionnaire for measuring of management style, there are five options for an answer: Characterizing to large extent (5), characterizing (4), difficult to decide (3), not characterizing (2), definitely not characterizing (1). The examined subject will be asked to address to each statement in the questionnaire according to extent of his agreement with content of the statement. There are 16 statements in the questionnaire for measuring existent management style in school. In a study by Cohen (2002), Cronbach Alfa of $\alpha=0.80$ was found, regarding existent management style.

\section{School Organizational Climate Questionnaire}

For the purpose of measuring school organizational climate, school organizational climate questionnaire by Zak (1981) was selected. The Hebrew phrasing as examined and validated by Zak (1985) as well as Dror (2001), was presented to the sample population, 44 items divided into seven dimensions. The reliability of the tool was examined according to Cronbach's Alfa system and $\alpha=0.86$ was found. For the entire tool Alfa spans between 0.86 and 0.88 for the items.

\section{Findings}

Regressions were conducted to examine the effect of management style on school climate. Additionally, after the schools were classified according to level of management decentralization, differences were examined in various variables that measure school climate, by conducting comparative $T$-tests between teachers' population in the various schools.

It was found that teachers in school A find management style in their school as decentralized regarding in relation to school teachers of school B. Additionally, teachers of school C find management style in their school as decentralized in relation to teachers of school B. It can be seen from the $T$-tests that in a comparison between schools A and B and in a comparison between schools C and B, average differences in these two comparisons were significant. In a comparison between schools $\mathrm{A}$ and $\mathrm{C}$, therefore, there is no significant difference in management style between schools A and $\mathrm{C}$. Thus, in the following comparisons we will examine whether the climate and its different components match the decentralization rating in the three schools (from the $T$-tests, schools A and C are most decentralized and school B is least decentralized).

\section{Results of Hypothesis A}

For examination of the hypothesis, we will conduct comparative $T$-tests to examine the differences of organizational climate averages between the schools.

Additionally, linear regression was conducted to examine the effect of decentralization level of management style on organizational climate. 
Table 1

Results of Comparing Averages of Answers to Questions of School Climate

\begin{tabular}{lllllll}
\hline School & $\mathrm{A}$ & $\mathrm{B}$ & $\mathrm{A}$ & $\mathrm{C}$ & $\mathrm{B}$ & $\mathrm{A}$ \\
\hline Mean & 3.39899 & 2.91866 & 3.39899 & 3.489234 & 2.91866 & 3.489234 \\
Variance & 0.067041 & 0.01517 & 0.067041 & 0.220349 & 0.01517 & 0.220349 \\
Observations & 18 & 19 & 18 & 19 & 19 & 19 \\
$t$ Stat & 7.268647 & & -0.71834 & & -5.12479 & \\
$P(T<=t)$ one-tail & $8.63 \mathrm{E}-09$ & & 0.238659 & & $5.13 \mathrm{E}-06$ & \\
$t$ Critical one-tail & 1.689572 & & 1.689572 & & 1.688298 & \\
$P(T<=t)$ two-tail & $1.73 \mathrm{E}-08$ & & 0.477318 & & $2.03 \mathrm{E}-05$ & \\
$t$ Critical two-tail & 2.030108 & & 2.030108 & & 28094 & \\
\hline
\end{tabular}

It can be seen from above Table 1, that teachers in school A consider the climate in their school to be good in relation to teachers of school B. Additionally, teachers of school C consider the climate in their school to be good in relation to school B teachers. The average differences in these two comparisons are significant. There is no significant difference between the climate in schools $\mathrm{A}$ and $\mathrm{C}$. The regression results are weakly significant $(p$-value $<0.1)$, and reflect a direct correlation between management decentralization level and school climate. Meaning that in a higher decentralization level we will receive a better school climate. Additionally, we received an explanation percentage $(R$-sq $=0.047)$, that is considered low. It shows that additional variables, besides management decentralization, affect school climate.

\section{Results of Hypothesis B}

For examination of the hypothesis, we will conduct comparative $T$-tests to examine averages differences of educational leadership between the schools. Additionally, a linear regression was made to examine the effect of management decentralization level on educational leadership.

Table 2

The Results of Comparison of Averages of Answers to Questions of School Educational Leadership

\begin{tabular}{lllllll}
\hline School & A & B & A & C & B & C \\
\hline Mean & 3.722222 & 2.807018 & 3.722222 & 4.122807 & 2.807018 & 4.122807 \\
Variance & 0.105752 & 0.069084 & 0.105752 & 1.418895 & 0.069084 & 1.418895 \\
Observations & 18 & 19 & 18 & 19 & 19 & 19 \\
$t$ Stat & 9.439213 & & -1.37803 & & -4.70181 & \\
$P(T<=t)$ one-tail & $1.88 \mathrm{E}-11$ & & 0.088471 & & $1.86 \mathrm{E}-05$ & \\
$t$ Critical one-tail & 1.689572 & & 1.689572 & & $3.72 \mathrm{E}-05$ & \\
$P(T<=t)$ two-tail & $3.75 \mathrm{E}-11$ & & 0.176941 & & 2.028094 & \\
$t$ Critical two-tail & 2.030108 & & 2.030108 & & & \\
\hline
\end{tabular}

From above Table 2, it can be seen that teachers in school A consider educational leadership in their school to be good in relation to teachers of school B. Additionally, teachers of school C consider educational leadership in their school to be good in relation to teachers of school B. Average differences in these two comparisons are significant. There is no significant difference in educational leadership between schools A and C. The regression results are weakly significant, $(P$-value $<0.1)$ and reflect a direct correlation between management decentralization level and school management leadership. Meaning, in a higher decentralization level we will receive a better leadership of school management. Additionally, we received an explanation 
percentage $(R$-sq $=0.056)$, which is considered low. This shows that there are additional variables, beside management decentralization, which affects the leadership of school management.

\section{Results of Hypothesis C}

For examination of the comparison, we will perform comparative $T$-tests to examine averages of adopting innovations between the schools. Additionally, a linear regression was conducted to examine effects of management style decentralization level on adoption of innovations.

Table 3

Results of Comparing Averages of Answers to Question on Adoption of Innovations

\begin{tabular}{lllllll}
\hline School & $\mathrm{A}$ & $\mathrm{B}$ & $\mathrm{A}$ & $\mathrm{C}$ & $\mathrm{B}$ & $\mathrm{C}$ \\
\hline Mean & 3.261905 & 3.428571 & 3.261905 & 3.774436 & 3.428571 & 3.774436 \\
Variance & 0.247899 & 0.156463 & 0.247899 & 0.302303 & 0.156463 & 0.302303 \\
Observations & 18 & 19 & 18 & 19 & 19 & 19 \\
$t$ Stat & -1.13057 & & -2.9667 & & -2.22581 & \\
$P(T<=t)$ one-tail & 0.132962 & & 0.002698 & & 0.016189 & 1.688298 \\
$t$ Critical one-tail & 1.689572 & & 1.689572 & & 0.032378 & \\
$P(T<=t)$ two-tail & 0.265923 & & 0.005396 & & 2.028094 & \\
$t$ Critical two-tail & 2.030108 & & 2.030108 & & &
\end{tabular}

From above Table 3, it can be seen that teachers in school A consider adoption of innovations in their school to be less good in relation to teachers of schools B and C (average differences are significant only between $\mathrm{A}$ and $\mathrm{C}$ ). Additionally, teachers of school $\mathrm{C}$ consider innovation adoption in their school to be good in relation to teachers of school B (averages difference in this comparison is significant). The regression results are not significant ( $p$-value $>0.1$ ), therefore, it is not possible to characterize according to the regression results the correlation between management style and adoption of innovations in school.

Table 4

Results of Linear Regression: Hypothesis C

\begin{tabular}{|c|c|c|c|c|c|}
\hline \multicolumn{6}{|l|}{ Regression Statistics } \\
\hline Multiple $R$ & 0.193112 & & & & \\
\hline$R$ square & 0.037292 & & & & \\
\hline Adjusted $R$ square & 0.019464 & & & & \\
\hline Standard error & 0.517421 & & & & \\
\hline Observations & 56 & & & & \\
\hline \multicolumn{6}{|l|}{ ANOVA } \\
\hline & df & SS & MS & $\mathrm{F}$ & Significance F \\
\hline Regression & 1 & 0.560022 & 0.560022 & 2.091786 & 0.153873 \\
\hline Residual & 54 & 14.45711 & 0.267724 & & \\
\hline \multirow[t]{2}{*}{ Total } & 55 & 15.01713 & & & \\
\hline & Coefficients & Standard error & $t$ Stat & $P$-value & \\
\hline Intercept & 2.631365 & 0.599301 & 4.390721 & $5.3 \mathrm{E}-05$ & \\
\hline Management style & 0.241755 & 0.167154 & 1.446301 & 0.153873 & \\
\hline
\end{tabular}

Summary: The comparison tests results partially reinforce the research hypothesis. The regression results in Table 4 are not statistically significant. 


\section{Results of Hypothesis D}

For examination of the hypothesis, we will perform comparative $T$-tests to examine the averages differences of sense of autonomy between the schools. Additionally, a linear regression was conducted for examination of decentralization level of management style on sense of autonomy.

Table 5

Results of Comparing Averages of Answers to Question on Sense of Autonomy

\begin{tabular}{lllllll}
\hline School & $\mathrm{A}$ & $\mathrm{B}$ & $\mathrm{A}$ & $\mathrm{C}$ & $\mathrm{B}$ & $\mathrm{C}$ \\
\hline Mean & 3.788889 & 3.410526 & 3.788889 & 3.284211 & 3.410526 & 3.284211 \\
Variance & 0.237516 & 0.117661 & 0.237516 & 0.183626 & 0.117661 & 0.183626 \\
Observations & 18 & 19 & 18 & 19 & 19 & 19 \\
$t$ Stat & 2.742942 & & 3.349831 & & 1.003101 & \\
$P(T<=t)$ one-tail & 0.004767 & & 0.000974 & & 0.161254 & \\
$t$ Critical one-tail & 1.689572 & & 1.689572 & & 1.688298 & \\
$P(T<=t)$ two-tail & 0.009534 & & 0.001947 & & 0.322507 & \\
$t$ Critical two-tail & 2.030108 & & 2.030108 & & 2.028094 & \\
\hline
\end{tabular}

From above Table 5, it can be seen that teachers in school A consider the sense of autonomy in their school to be good in relation to teachers of schools B and C. These two comparisons yielded significant results. Between teachers of school $\mathrm{C}$ and teachers of school B no significant difference was found. The regression results are not significant $(P$-value $>0.1)$, therefore it is not possible to characterize the correlation between management style and sense of autonomy of school teachers according to results of the regression.

Table 6

Results of Linear Regression: Hypothesis D

\begin{tabular}{|c|c|c|c|c|c|}
\hline \multicolumn{6}{|c|}{ Regression Statistics } \\
\hline Multiple $R$ & 0.215069 & & & & \\
\hline$R$ square & 0.046255 & & & & \\
\hline Adjusted $R$ square & 0.028593 & & & & \\
\hline Standard error & 0.46025 & & & & \\
\hline Observations & 56 & & & & \\
\hline \multicolumn{6}{|l|}{ ANOVA } \\
\hline & $\mathrm{df}$ & SS & MS & $\mathrm{F}$ & Significance $\mathrm{F}$ \\
\hline Regression & 1 & 0.554761 & 0.554761 & 2.618901 & 0.111424 \\
\hline Residual & 54 & 11.43881 & 0.21183 & & \\
\hline \multirow[t]{2}{*}{ Total } & 55 & 11.99357 & & & \\
\hline & Coefficients & Standard error & $t$ Stat & $P$-value & \\
\hline Intercept & 2.632357 & 0.533083 & 4.937986 & $7.98 \mathrm{E}-06$ & \\
\hline Management style & 0.240617 & 0.148685 & 1.618302 & 0.111424 & \\
\hline
\end{tabular}

Summary: The results of comparison tests in Table 6, show partially that decentralization in management brings about improvement in sense of autonomy. The regression results are not statistically significant.

\section{Discussion of Research Findings}

From results of the study, it can be seen that teachers in school A (control group) consider management style in their school as decentralized in relation to school B teachers. Additionally, teachers of school C 
consider management style in their school as decentralized in relation to teachers of school B. Averages differences in these two comparisons are significant.

There is no significant difference in management style between schools A and B. Therefore, comparisons were made that examined the components of schools climate and following are the results and evaluation of their validity:

Teachers in schools $\mathrm{A}$ and $\mathrm{C}$ consider educational leadership in their school to be good in relation to teachers of school B-significant results. Similar findings are found by Dror (2001) who found that positive school climate created was an outcome of supporting leadership and cooperation between the principal and teachers.

Teachers in school A consider adoption of innovations in their school to be less good in relation to teachers of schools B and C (average differences are significant only between A and C). Additionally, teachers of school $\mathrm{C}$ consider innovation adoption in their school to be good in relation to teachers of school B (average differences in this comparison are significant).

Bogler (2001) claimed that leadership style based on change and innovation employed by schools' principals affected satisfaction of teachers. As claimed by Levy (2008), leadership currently is more related than before to ability of leading constant changes and innovation. As opposed to current study, results of comparison tests reveal that decentralization in management style not necessarily bring about adoption of innovations in school A. However, results of the regression are not statistically significant.

Teachers in school A consider sense of autonomy in their school to be good in relation to teachers of schools B and C. Those two comparisons yielded significant results. No significant difference was found between teachers of school C and teachers of school B. This finding is similar to findings of Golan (1995), who examined the linkage between development of autonomy foundations in a school and schools' perception of management style of a school principal.

(1) Differences were found between teachers in perception of school characteristics as providing various levels of autonomy. No school is similar to another.

(2) All teachers report their school principal as leading the school towards changes and innovations.

(3) No correlation was found between personal background variables and perceptions of teachers regarding principal's management style.

(4) The principal has a central role in a schools' perception of professional autonomy. The sense of professional autonomy of a teacher is reinforced the more a teacher senses that the principal is an educational figure or a leader whom he can consult with on personal and professional problems.

Teachers in school A consider the climate in their school to be good in relation to teachers of school B. Additionally, teachers of school $\mathrm{C}$ consider the climate in their school to be good in relation to teachers of school B. The average differences in these two comparisons are significant. There is no significant difference in climate between schools A and C. This finding answers the main question and hypothesis of the study: Indeed, decentralized management style affects the creation of school positive organizational climate.

\section{Summary of Conclusions and Recommendations}

In the description of research field, it was indicated that there are three schools from the Arab sector which include similar cross-section of population and teaching staff. Despite this, findings of the study determine that the principal of school B is less decentralized and more authoritative than in the other schools. 
Indeed the data of school B are different from rest of the schools in following details: It is the largest, and the teachers are veterans, and it is managed by a "new female principal". It is possible that connection of veteran teachers, a new female principal, meaning to say a "woman principal" in the Arab sector, is the reason that causes teachers to evaluate her as authoritative rather than decentralized. Therefore, our recommendations to school principals are: To demonstrate openness and honesty (Shechter, 2002), to reduce his self and allow the staff that works with him of expression possibility, he is required of constant improvement and constant learning. To learn and change and lead changes. To expect and to predict for the long term regarding the future of his pupils, the staff and the community. To insist on important things without nullifying himself in front of others (Dagan, 2000). To maintain a combination of both approaches of accomplishing missions as well as the good feeling of staff members. To support and appreciate the people working with him. To create an open climate. To consult and guide the teachers in various fields such as teaching methods, violence, resolution of problems and discipline. To provide resources and control the use thereof (Fisher, 2003). To know how to evaluate teaching programs and methods, study books (Dagan, 2000). To be characterized by listening capability. To exhibit empathy. To have self-awareness (Bigger, 2003). To understand the multiple context the school operates in political, social, economic, legal, and cultural fields, to have strong and reasonable personality that can withstand pressures (Dagan, 2000).

In summary, it is possible to say that it is difficult to evaluate the work of a principal due to the fact that his work is complex, having many facets and dependent upon context. In an attempt to respond to these difficulties, various methods were employed. One of the ways to sort the evaluation is "360 degrees feedback" for principals' evaluation. The method is considered as one of the most effective tools to evaluate performance of a principal, see for example an up-to-date study, conducted on 785 managers in American Tax Authority (Levy, 2008). Therefore, the researchers recommend to conduct a future study as a research thesis for Master's degree which would include: Quantitative research similar to current study in which the sample population will be increased to 156 teachers from all schools of the Arab sector. For purpose of validation, "360 degrees feedback" questionnaire will be used, similarly to that of the study of Trivka (Levy, 2008).

\section{References}

Bigger, H. (2003). The kindergarten teacher as manger and educational leader. Kindergarten Echo, 68(1), 14-18.

Bogler, R. (2001). Impact of leadership style on teacher job satisfaction. Educational Administration Quarterly, 37, 662-683.

Cohen (Zaafrani), A. (2002). Professional self-image of teachers and its context to management style and socio-demographic variables of a teacher. Master's degree thesis. Ramat-Gan: Bar-Ilan University, Department of Education.

Dagan, M. (2000). Leadership and management. Sde Hemed, 44(3-1), 131-147.

Dror, A. (2001). Correlation between school climate, sense of efficacy of teachers and attitudes of teachers towards integration of pupils with special needs. Tel-Aviv: Tel-Aviv University, Department of Education, Developmental Aspects program.

Fisher, Y., \& Friedman, Y. (2003). Organizational management pyramid model: Feedback-based model. Reviews in Administration and Organization of Education, 27, 153-175.

Friedman, Y. (1993). Leadership and team ripeness-A model for change introducing school principals. Reviews in Administration and Organization of Education, 9, 29-46.

Friedman, Y. (1995). Being a school principal: Pressure, burnout and coping. Jerusalem: Henrietta Szold Publication.

Friedman, Y. (1995). School climate and class climate: Professional literature review. Jerusalem: Henrietta Szold Publication.

Friedman, Y. (2004). A teacher as an organizational vocational personnel: Ideals of giving and expectations of receiving. Reviews in Administration and Organization of Education, 28. Center of Administration and Evaluation in Education, Haifa University.

Golan, H. (1995). Teachers' perceptions in various autonomous environments of school principal (eight case studies). Master's degree thesis. Tel-Aviv: Tel Aviv University, Department of Education. 
Golman, D. (2000). Leadership that achieves results, 2000. Executive (April-May), 20-31.

Hen, Y., \& Mor, M. (2004). Management perceptions of post-primary school principals and dimension of peer tolerance. Reviews in Administration and Organization in Education, 28, 37-61.

Levy, E. (2008). Management and leadership change and innovation. Rimonim Publication.

Ministry of Education, School Administration Unit. $360^{\circ}$ feedback for evaluation of principals. Monthly Journal for Promotion of Leadership, Professionalism, Proficiency and Excellence in School Administration in Primary Education, no. 10, 2007.

Oplatka, Y. (2010). Basics of educational administration, leadership and management in educational organization. Haifa: Pardes. Sergiovanni, T. J. (2002). School management theoretical and practical aspects. Tel-Aviv: Open University.

Shechter, H. (2002). Authentic leadership in the educational system. Reviews in Administration and Organization of Education, 26, 69-92.

Somech, A., \& Reiter, S. (2005). Perception of duty of a principal in Arab sector-Effect of management style and organizational climate on school effectiveness. Reviews in Administration and Organization of Education, 30, 37-61.

Zafrir, S. (2003). Management styles of junior-high and high school principals in comprehensive six-year schools and their linkage to the six-year interaction problems. Eye Contact, 32, 20-21.

Zak, I., \& Horowitz, T. (1985). School is also the world of a teacher. Tel-Aviv: Ramot Publication.

Zak I. (1981). School's organizational climate. In A. Levy and D. Nevo (Eds.), Evaluation roles in education (pp. 409-432). London: Gordon \& Breach. 